\title{
Predicting environmental factors influencing crop raiding by African elephants (Loxodonta africana) in the Luangwa Valley, eastern Zambia
}

\author{
Vincent R. Nyirenda ${ }^{1,2}$, Willem J. Myburgh ${ }^{1}$ and Brian K. Reilly ${ }^{1}$ \\ ${ }^{1}$ Department of Nature Conservation, Faculty of Science, Tshwane University of Technology, Private Bag X680, \\ Pretoria, South Africa. \\ ${ }^{2}$ Directorate of Research, Zambia Wildlife Authority, Private Bag 1, Chilanga, Lusaka, Zambia.
}

Accepted 17 September 2012

\begin{abstract}
Elephant crop raiding is pervasive and widespread in elephant-agriculture landscapes. Due to rare investigations on underlying African elephant (Loxodonta africana) crop raiding processes and patterns, neither reliable predictive models nor empirical evidence on elephant crop raiding parameters are available or adequate to support intervening decisions by susceptible farmers and other stakeholders. By developing predictive models of binary logistic regression and employing questionnaire surveys, we examined the environmental factors influencing occurrence of crop raiding by interrogating effectiveness of counter-measures implemented by local farmers in Luangwa Valley, eastern Zambia. Farm sizes, vegetation types in peripherals of crop fields and types of countermeasures used by local farmers to restrain marauding elephants were the most important elephant crop raiding predictors. Smaller crop fields $\left(\leq 4782.00 \pm 342.00 \mathrm{~m}^{2}\right)$ were more vulnerable than larger ones. Most crop fields $(75.88 \%, n=236)$ surrounded by Brachystegia and Acacia dominated vegetation communities were damaged, largely due to high tree fruiting which were elephant attractants. Solar powered electric fences were more effective than other counter-measures. Though traditional methods were prevalent, they were less effective than other counter-measures. It was posited that additional capacity development of local farmers was required particularly, in participatory integrative land use practices to minimize elephant crop raiding.
\end{abstract}

Key words: Predictive models, elephant crop raiding, conservation, Luangwa Valley, Zambia.

\section{INTRODUCTION}

According to Hoare (2001), "any human-elephant interaction which results in negative effects on human social, economic or cultural life or elephant conservation or the environment" defines human-elephant conflicts (HECs). However, human-elephant interaction becomes a conflict when people experience, perceive and interpret them as producing negative impact (Riley et al., 2003; Madden, 2006). Whereas the conditions for each HEC may be unique, the key driver of such a conflict is competition for space and resources (Balmford et al.,

${ }^{*}$ Corresponding author. E-mail: nyirendavr@hotmail.com. Tel: +260211278 683. Fax: +260211278524.
2001). In sub-Saharan Africa, like in many parts of Africa, HEC incidences have been increasing, thereby posing great challenge to wildlife conservation (Lamarque et al., 2009). HECs have become widely spread as expanding agriculture increases human-elephant interface (Hoare, 1999) and occur wherever humans come into contact with elephants (Sitati et al., 2003). The interactions have a wide array of emerging impacts, events or simply conflicts, which include: crop raiding; damage to infrastructure like houses, food stores, fences and other barriers; occasional injuries and demise of people on one hand. On the other hand, habitat loss to elephants and retaliatory killing of elephants by inflicted people take place. As a HEC hotspot, Luangwa Valley experiences numerous, pervasive and widespread elephant crop 
raiding incidences.

According to Naughton-Treves (1998) and Wittemyer et al. (2008), HECs intensify in 'refugia' and adjoining areas to national parks. These are areas where wildlife populations are concentrated in higher abundance than elsewhere. The concept of refugia presumes that elephants prefer to move little, drink easily, eat well, and avoid people (Harris et al., 2008). Therefore, with diminishing wildlife habitats due to human encroachment (Lewis, 2007), elephant habitats are degraded, forcing the increasing elephant population to expand their ranges (Junker et al., 2008). In such HEC situation, local inhabitants gain easy illegal access to elephants (Hoare, 1999). Once the animal habitats have been encroached, local inhabitants may be unable to fully provide their food needs, especially, when their crops have been devoured by elephants. Therefore, they may resort to illegal offtakes for food security. For instance, Lewis and Phiri (1998) contend that food shortages coerce local farmers to engage in deleterious snaring of animals in Luangwa Valley, Zambia. Crop raiding negatively impacts on rural food and livelihood security for the impoverished farmers as extensive food crop damage by elephants diminishes their yields, causing nutritional stress and depleting food reserves. Thus, food deprivation for active and health life at any time, consistitutes food insecurity $(F A O, 2008)$ and has potential of eroding local support for biodiversity conservation (O'connell-Rodwell et al., 2000; Gadd, 2005).

In accordance with observations by Sitati et al. (2005), that any intended mitigation required a detailed understanding of underlying processes and patterns associated with elephant crop raiding incidences, this study aims at exploring environmental factors, alongside crop raiding counter-measures. Underlying crop raiding factors are determinants; processes are succession of events giving rise to impacts, while patterns are spatiotemporal layout of crop raiding events. These processes and patterns can vary in space and time. In order to comprehend the complexities embedded in the resultant processes and patterns, we require determining predictors of elephant crop raiding. Several past studies treat environmental parameters in isolation when in fact the parameters are simultaneously influencing the occurrence of elephant crop raiding. Therefore, we hypothesize that predictors did not impact on crop raiding occurrences in the same way but in varying degrees and each with partial contribution. The question we answer is: which one of the environmental factors are the most important? Such knowledge would help in improving decision-making processes in HEC management.

Our focus in this article is on spatial scope of environmental factors and therefore, we do not delve into temporal parameters. We also assumed that environmental factors dictated what counter-measures were applicable by local farmers to protect their crops. Further, we posit that efficacy of counter-measures influences the outcome of raiding effort by elephants. Thus, Reilly and Reilly (2003) define effectiveness as a measure of productivity in the use of local resources in short term, bearing profitability in long term. It is assumed that farmers comprehend better than assessors from outside the magnitude and nature of elephant damage, specific interventions and their impacts (Nyhus et al., 2005). They are the best judges over the effectiveness of the countermeasures (Taylor, 1993). This study investigates determinants of elephant crop raiding to guide decision making, especially, in respect to HEC interventions in the Luangwa Valley, Zambia, which is a 'hotspot'. The relevance of the study is that its findings would better equip farmers' and other stakeholders' hegemony over elephant crop incursions and allow for food and livelihood security.

\section{MATERIALS AND METHODS}

\section{Study site location}

Lupande Game Management Area (GMA), covering an area of 4840 $\mathrm{km}^{2}$ constitutes the study area, which is located at $12^{\circ} 57^{\prime}$ to $13^{\circ} 49^{\prime} \mathrm{S}$ and $31^{\circ} 32^{\prime}$ to $32^{\circ} 23^{\prime} \mathrm{E}$ in central Luangwa Valley, eastern Zambia (Figure 1). It is principally a customary land under purview of traditional leadership.

\section{Human demography and socio-economic characteristics}

The estimated human population in Lupande GMA, as determined from available census record, is over 47376 people (Central Statistical Office) (CSO, 2003). The people of central Luangwa Valley have a long history of living with wildlife as evidenced by animal and plant fossils, forming "footprints" of human-wildlife interactions. Another anthropogenic evidence of Luangwa Valley people's interactions with wildlife is through their culture, demonstrated by people's names, songs and dances, dressing and to some extent culinary habits. Subsistence agriculture is the mainstay as a source of revenue and food. Crops are mostly cultivated in mono-specific stands on varying crop farm sizes and shapes, and crop varieties include; maize (Zea mays), cotton (Gossypium hirsutum), millet (Eleusine sp.), sorghum (Sorghum vulgare), beans (Phaseolus vulgaris), pumpkin (Curcubita maxima) and sweet potato (Ipomoea batatas). Crop production, however, is constrained by first, crop raiding by wild animals, causing food insecurity (Lewis and Phiri, 1998; Simasiku et al., 2008) and secondly, by high incidences $(60 \%)$ of drought (Gilvear et al., 2000). Other economic activities in the Luangwa Valley are artisan fishing, timber harvesting, photographic tourism and safari hunting businesses.

\section{Vegetation communities}

Phiri (1994) and Smith (1998) characterized vegetation types of the Luangwa Valley, as being predominantly Brachystegia dominated Miombo woodlands on the plateau and a mosaic of vegetation types on the valley floor, constituting Miombo-Mopane, AcaciaCombretum, Faidherbia-Combretum, Colophospermum Mopane and riparian woodlands. Crop farms are situated in these diverse vegetation types. The vegetation communities occupy six distinguishable topographic units of relief and topography in the 
Luangwa Valley, from escarpment zone, hill zone, ridges and high undulating surfaces, plains and pans and old alluvial zone to floodplains (Gilvear et al., 2000).

\section{Climate}

There are three distinct climatic seasons: hot-wet season from late November to April; a cool-dry season from May to August; and a hot-dry season from September to early November. The study area is situated in the agro-ecological zone I of Zambia, with mean annual rainfall $\leq 830 \mathrm{~mm}$ per annum in the valley trough whereas records in excess of $1220 \mathrm{~mm}$ per annum are noted in the northern sector of the Luangwa Valley. The mean daily maximum temperature ranges from 32 to $36^{\circ} \mathrm{C}$ in the hot season. The minimum mean temperature in the cold season (June to July) is $15^{\circ} \mathrm{C}$ and maximum mean temperature in hot season (October) is $36^{\circ} \mathrm{C}$ in the valley floor. On the escarpment and surrounding areas, it is colder and less arid than on the valley floor as observed several decades ago by Archer (1971).

\section{Elephant as a problem animal}

According to McIntyre (2004), the Luangwa Valley $\left(144000 \mathrm{~km}^{2}\right)$ is one of the areas in Africa with high species diversity and large elephant population size. For instance, the country-wide survey conducted by Simukonda (2008) shows that $72 \%(n=18 ; 634 \pm$ 3592) of Zambia's elephant population inhabit the Luangwa Valley. The large African elephant population size results in increased conflicts as elephants compete for food and space (Balfour et al., 2007). Elephants cause preponderance crop damage in terms of frequency and severity compared to other sympatric problem wild animals in the Luangwa Valley (Nyirenda et al., 2011)

\section{Data capture protocols}

Elephant crop damage datasets as response variable were collected from six chiefdoms (Jumbe, Kakumbi, Malama, Mkhanya, Msoro and Nsefu) (Figure 1) of Lupande GMA during wet farming seasons of 2007-2008. Ten explanatory environmental variables examined were: vegetation type; distance in metres to national park, distance to roads, distance to rivers, peripheral vegetation; elevation in degrees, farm size in square metres, farm shape, and counter-measure implemented by local farmers. Due to the nature of agricultural landscape of mono-specific crop cultivation, crop types were not fostered in the predictive models as they were strongly correlated, causing co-linearity in subsequent data handling.

Response variables were randomly sampled with sample size $\mathrm{n}=82$ in six chiefdoms (Figure 1) from elephant crop raiding incidences, which were adequate for statistical analysis. The geospatial data were gathered at the level of crop farms, which was appropriate resolution in accordance with Sitati et al. (2003). In this way, spatial autocorrelation was avoided (Koenig, 1999), such that the possibility of committing type I error was minimized or excluded altogether (Reilly and Reilly, 2003). A combination of inductive and deductive data driven models were developed, integrated with expert knowledge, whereby the resultant predictive models followed the steps of inquiry and discovery.

Field data was collected with the help of six trained field enumerators. At each farm, physical imprints such as foot prints, dung droppings and animal feeding habits to determine the crop raiding species, an approach described by Kagoro-Rugunda (2004), where crop raiding animal was not seen by the complainant were adopted. Field assessments were derived from investigation of site remnants in comparison with immediate surrounding. The name of the vegetation type surrounding the farm was recorded. Geographical location and elevation of the central position of each farm was obtained using geographic positioning system (GPS) and subsequently distances in a straight line to nearest national park, road, river, peripheral vegetation and established local and national forest within the study area were geo-referenced in GIS environment. The farm area dimensions were estimated by graduated paces, which were then converted to metric measurements (Chiyo et al., 2005). These dimensional measurements for peripherals of the farms were made using a series of regular shapes in form of polygons (Chiyo et al., 2005). The farm shapes included multiangular, rectangular, wavy, triangular, square and concave shapes. Each crop type was categorized by its quality of poor, medium or good and the stage of growth of seedling, intermediate or mature by use of proximate expert judgment at the time of damage. Crop depredation was recorded on the form, capturing data on crop quality, growth stage and area damaged in comparison to the total farm area.

\section{The questionnaire survey}

Structured questionnaires were administered with the help of six trained field enumerators between 2008-2010, to gather data on perception of farmers on effectiveness of the counter-measures practiced in accordance with the protocols proposed by Bradburn et al. (2004) from 482 respondents, stressing pre-testing, use of choice of answers in menu and disclosure of confidentiality of responses. The respondents were drawn from 103 villages of the six chiefdoms of Lupande GMA. Effectiveness was derived by frequency normative rating of crop raids as "very high" (reducing crop raids by $>75 \%$ ), "high" (reducing crop raids by 50 to $75 \%$ ), "moderate" (reducing crop raids by 30 to $50 \%$ ) and "low"( reducing crop raids by $<30 \%)$.

\section{Analyses}

Minitab statistical and ArcView GIS software were used in the analyses. Data was classified according to whether it was categorical (discrete) or continuous. Categorical data was allotted " 1 " if crop damage took place or " 0 " if the field was unscathed and each element of farm shapes and counter-measures variables was allocated a different number from the other. Numerical variables for distance and elevation measurements were transformed to achieve normality in distribution based on Fowler et al. (2006). Stepwise binary logistic regression techniques were employed to categorical data for the response variable as described by Nicholls (1989) and Gausan et al. (2002). Variable selection was conducted in iterations of "Forward Stepwise Selection". Each independent variable was added alone to the null log-linear model $(n=82)$. Succeeding iterations were made to improve the building of the statistical model. Only variables having the maximum likelihood estimator that would improve the model were selected. Thus, the choice for model building was based on a set of parameters for which the loglikelihood was highest (Crawley, 1994). At the end of each iteration, change in deviance resulting from the addition of a variable to the model was determined. Transformation in the risk for any additional unit of the independent variable was quantified by the exponent of the regression coefficient, $e^{b}$ (Selvin, 2004). The model specifications took the general forms based on Equations 1 and 2 by Nicholls (1989) as:

$$
\begin{aligned}
& y_{i}=\exp \left[a+b_{1} x_{1}\right] \\
& y_{i}=\exp \left[a+b_{1} x_{1} \ldots . .+b_{n} x_{n}\right]
\end{aligned}
$$

Where $y_{i}$ represents predicted response (absence or presence), a 
Table 1. Relationship between farm size, severity of damage and mean area cultivated, mean area damaged and percentage damaged in Luangwa Valley, Zambia, during 2004-2008 crop farming seasons (dry season farming statistics in parentheses).

\begin{tabular}{lccccc}
\hline Severity & Fields surveyed $(\mathbf{n})$ & $\begin{array}{c}\text { Area cultivated }\left(\mathbf{m}^{2}\right) \\
\text { Mean } \pm \text { SE }\end{array}$ & Farm size category & $\begin{array}{c}\text { Area damaged }\left(\mathbf{m}^{2}\right) \\
\text { Mean } \pm \text { SE }\end{array}$ & $\begin{array}{c}\% \text { Damaged } \\
\text { Mean } \pm \text { SE }\end{array}$ \\
\hline High & \multirow{2}{*}{$310(75)$} & $4782.00 \pm 342.00$ & Small & $2183.00 \pm 165.00$ & $53.02 \pm 1.90$ \\
& & $(2514.00 \pm 348.00)$ & & $(1122.00 \pm 183.00)$ & $(50.01 \pm 3.89)$ \\
Medium & $722(50)$ & $8553.00 \pm 762.00$ & Medium & $334.40 \pm 22.60$ & $6.04 \pm 0.28$ \\
& & $(3771.00 \pm 543.00)$ & & $(209.70 \pm 45.90)$ & $(6.41 \pm 0.90)$ \\
Low & $93(1)$ & $8614.00 \pm 1184.00$ & Large & $215.70 \pm 45.70$ & $2.70 \pm 0.26$ \\
& & $(3000)$ & & $(109)$ & $(3.63)$ \\
Total & $1125(126)$ & & & & \\
\hline
\end{tabular}

and $b_{1}-b_{n}$ being intercept and slope parameters respectively for one or $n$ independent variables $\left(X_{1}-X_{n}\right)$. A G-test was used to test the significance of association of the frequencies in response variable as function of the selected variables into the models.

Severity of crop raiding in the Luangwa Valley for 2004 to 2008 crop farming seasons was determined based on Malima et al. (2005). Combined score was derived from the crop growth stage, quality and extent in percentage of damage in the crop field at the time crop damage occurred. Crop growth stage of seedling, intermediate or mature was allotted one, two or three points respectively. Crop condition in terms of whether the crop was in poor, medium or good status, determined from crop vigour was respectively given one, two or three points. Percentage of the damage was allotted six points based on whether it was $\leq 5 \% ; 5.1$ to $10.9 \%$; 11 to $20.9 \%$; 21 to $50.9 \%$; 51 to $80 \%$; or $>80 \%$ as one, two, three, four, five or six. Though use of percentage was relative from local farmers' perspective, perception of severity of crop damage was associated with spatial proportion of crop fields damaged. By categorizing severity and area cultivated, corresponding farm sizes were determined. Additive combined scores were then apportioned as low ( $\leq$ five points), medium (six eight points) or high ( $\geq$ nine points) damage classes.

\section{RESULTS}

\section{Severity of invasion}

Farm sizes in the sample size varied from 726 to 50000 $\mathrm{m}^{2}$, with median of $7500 \mathrm{~m}^{2}$. The small farms (mean \pm SE; $4782.00 \pm 342.00 \mathrm{~m}^{2}$ ) were predated more than the large ones (mean \pm SE; $8614.00 \pm 1184.00 \mathrm{~m}^{2}$ ) (Table 1). They were damaged as much as $53 \%$ of the total farm area in wet season. Similarly, small crop fields were more susceptible to elephant crop raiding than large crop fields in the dry season.

\section{Variable selection and model building}

There were 82 crop farms (32.67\%) sampled during 2007/2008 farming season in six chiefdoms out of 251 invaded crop fields. Major predictors for crop depredation by elephants in the multivariate models were farm sizes (FS), vegetation types (VT) around the crop fields and key counter-measures (CM) in place (Table 2). Equation
3 confirmed that small crop fields were significantly more vulnerable to elephant crop raiding than the large farms. The rate of change per unit increase in farm sizes did not result in large changes for the response variable. However, increasing farm size by one square meter did not reduce the chances of occurrence of one more incursion; thus, $e^{b}=0.014$ (Table 2) given as:

$\mathrm{Y}=\exp [14.468-4.281 \log (\mathrm{FS})]$

Log-likelihood $=-28.711 ; G=23.322 ; d f=1 ; p<0.001$

Crop fields were associated with different vegetation types, which included Brachystegia dominated Miombo woodlands, riparian vegetation, C. Mopane woodlands, Acacia woodlands, grasslands and scrublands. Most of crop fields $(75.88 \%, n=236)$ surrounded by Miombo vegetation communities and Acacia woodlands were damaged and significantly vulnerable than others as depicted by regression analysis (Equation 4). Association of a particular vegetation type increased or reduced chances of elephant crop raiding by as much as 1.725 times (Table 2) given as:

$\mathrm{Y}=\exp [0.512(\mathrm{VT})-3.386]$

Log-likelihood $=-36.137 ; G=8.564 ; d f=1 ; p=0.003$

The main counter-measures were solar powered electric fences, Capsicum fences and traditional measures. Traditional measures included use of guard huts, noise creation to scare animals away, wood fires creation in chosen parts of crop field boundaries particularly in known gateways of the elephants, use of trajectories such as stones, metal bars and wood pieces, and occasionally use of decoy foods with chilli Capsicum seeds embedded in it. The kind of counter-measures implemented significantly influenced crop incursions incidences (Equation 5). A unit of increase in different counter-measures resulted in large differences in the outcomes of the response variable. By changing countermeasures, the chance of invasion reduced or increased 
Table 2. Iteration-Null linear model as a function of independent variables for elephant crop raiding incidences in the Luangwa Valley, Zambia, during 2007 to 2008 crop farming season.

\begin{tabular}{lcccccc}
\hline Parameters & $\begin{array}{c}\text { Change in } \\
\text { deviance }\end{array}$ & $\begin{array}{c}\text { Regression } \\
\text { coefficient b }\end{array}$ & $\mathbf{e}^{\mathbf{b}}$ & pcal & pstd & Rank \\
\hline Log (farm size) & 28.711 & -4.281 & 0.014 & $0.001^{\star * *}$ & $<0.001$ & 1 \\
Vegetation type & 36.137 & 0.512 & 1.669 & $0.003^{\star \star *}$ & $<0.05$ & 2 \\
Counter-measures & 36.465 & 2.478 & 11.917 & $0.005^{* * *}$ & $<0.05$ & 3 \\
Elevation & 37.629 & -0.019 & 1.019 & 0.057 & $>0.05$ & 5 \\
Log(distance from the river) & 37.710 & 1.341 & 3.822 & 0.061 & $>0.05$ & 4 \\
Farm shapes & 39.142 & -0.197 & 0.821 & 0.415 & $>0.05$ & 6 \\
Log (distance from national or local forests) & 40.118 & -0.540 & 0.583 & 0.501 & $>0.05$ & 7 \\
Log (distance from major roads) & 40.314 & 0.269 & 1.309 & 0.588 & $>0.05$ & 8 \\
Log (distance from vegetation) & 40.391 & 0.001 & 1.001 & 0.645 & $>0.05$ & 9 \\
Log(distance from the park) & 40.627 & -0.119 & 0.888 & 0.896 & $>0.05$ & 10 \\
\hline
\end{tabular}

***-statistically significant; $e^{b}$ - exponent of the regression coefficient; Pcal-calculated $p$-value; Pstd -set allowable $p$-value.

by more than ten times, thus, $e^{b}=10.237$ (Table 2) is given as:

$\mathrm{Y}=\exp [2.478(\mathrm{CM})-6.156]$

Log-likelihood $=-36.465 ; G=7.272 ; d f=1 ; p=0.005$

Proximity to national park, adjoining vegetation, road, national or local forest as well as farm shape were not significant at $\mathrm{p} \leq 0.005$ in these models and were discarded. Farm size alone was a significant predictor of crop raiding in the Luangwa Valley at $p \leq 0.005$. Adding vegetation types to the model significantly improved the linear model (Equation 6). Other independent variables did not significantly improve the linear model. As such, the level of statistical significance halted the building of the linear model. Further iterations by adding independent variables to predictive model as a function of farm size and vegetation type were ineffective. Equation 6 is given as:

$\mathrm{Y}=\exp [11.211-3.653 \log (\mathrm{FS})+0.412(\mathrm{VT})]$

Log-likelihood = -26.213; $G=28.100 ; d f=2 ; p<0.001$

Equation 7 depicts the function relationship among three parameters of farm size, vegetation types and countermeasures given as:

$\mathrm{Y}=\exp [0.579(\mathrm{VT})-0.001 \log (\mathrm{FS})+1.423(\mathrm{CM})-6.004]$ (7)

Log-likelihood = -31.663; $G=17.196 ; d f=3 ; p<0.001$

\section{Model evaluation}

Adequacy of the model was determined by G-test and only independent variables that had significant statistical probability were retained. Such variables were farm sizes, surrounding vegetation types and counter-measures applied on the respective farms. The hypothesis that was tested could be formulated as: Was the model with $n+1$ parameters better than a model with $n$ parameters?

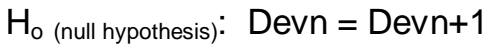

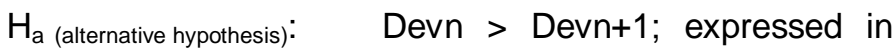
terms of log-likelihood.

\section{Contemporary counter-measures}

Traditional counter-measures were perceived by local farmers $(n=482)$ as most prevalent but ineffective, except where collaborative guarding was employed (Table 3). Disturbance counter-measures constituted scaring away of the animals by fired blanks (blasting) by wildlife agency, which was also largely ineffective especially where disturbance methods were infrequent and shortened. Influenced by application skill and frequency of use, experimental repellents which made use of Capsicum were also ineffective. Physical barriers around the farms or on a portion identified by the farmer as 'hotspots', particularly in Malama Chiefdom (Figure 1) were effective where solar powered electric fences protected 34 farmers' crop fields that were surveyed. In other five Chiefdoms, $51.45 \%$ of the surveyed farmers had live plant fencing. Physical barriers were effective methods against elephant crop raids as attributed by $92.42 \%$ farmers who applied the measure. Killing of problem elephants was mainly conducted by wildlife agency and covered $<1 \%$ of incidences per annum. In some cases, elephants were killed by local communities themselves by incidences of retribution. Local farmers perceived killing of problem elephants as ineffective as remaining elephants continued invading crop fields. Land use practices involved planning of fields, settlements placement and implementation of perceived novel but less vulnerable crops such as Capsicum and Jatropha. The measures aimed at reducing spatial competition between human and elephants were perceived by local 
Table 3. Count of counter-measures employed by local farmers against elephant crop invasions and their perceived effectiveness ratings in the Luangwa Valley, Zambia, 2008-2010.

\begin{tabular}{lccccc}
\hline \multirow{2}{*}{ Type of counter-measures } & \multicolumn{6}{l}{ Rating of counter-measure effectiveness } \\
\cline { 2 - 6 } & Very high & High & Moderate & Low & Total \\
\hline Traditional & 0 & 13 & 47 & 177 & 237 \\
Disturbance & 7 & 19 & 34 & 42 & 102 \\
Experimental & 9 & 12 & 22 & 34 & 77 \\
Physical barrier & 9 & 25 & 13 & 5 & 52 \\
Killing & 0 & 0 & 5 & 4 & 9 \\
Land use practices & 5 & 0 & 0 & 0 & 5 \\
\hline
\end{tabular}

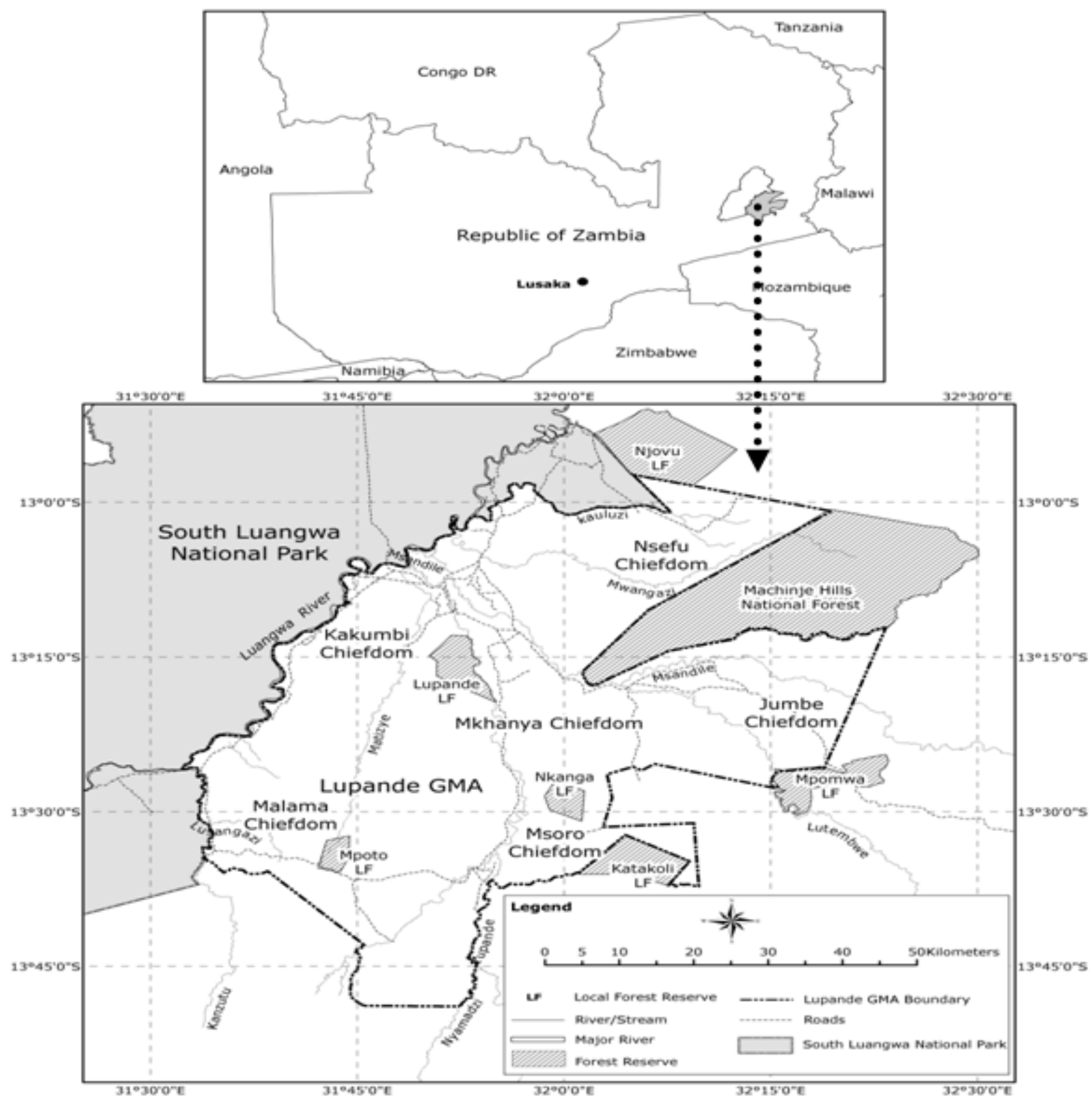

Figure 1. Location of Lupande Game Management Area in eastern Zambia. 
farmers as not common though highly effective.

\section{DISCUSSION}

\section{Predictors of crop raiding}

Previously, studies on wildlife crop raiding implicated mean proximity to forest edge, national parks, rivers, guarding measures, human densities and settlements, lunar phase; rainfall and season, forage quality, fruiting diversity and availability (Barnes et al., 2006; Chiyo et al., 2005; Danquah et al., 2006; Naughton-Treves, 1998; Sitati et al., 2005). In Luangwa Valley, smaller crop fields were more vulnerable than larger ones as they were mostly spatially isolated and did not exist in clusters. Larger crop fields received more attention and investment in guarding by farmers. Mono-specific cropping was practised more on larger crop fields than smaller fields that contained a greater variety of crops which attracted elephants.

High concentrations of fruiting trees such as Sclerocarya caffra, Ziziphus mauritiana, Tamarindus indica and Borassus sp. in Acacia woodlands were attractants to elephants. In past studies, Parker and Osborn (2001) postulated that elephants could be attracted by fruiting trees of $S$. caffra around the crop fields in the mid-Zambezi valley. Fruiting trees increased the probability of elephant encroachment into crop fields. In Brachystegia dominated Miombo woodlands, major attractants were probably tree debarking activities.

Water availability could be a key limiting factor in the dispersal of elephants in dry season (Chamaillé-Jammes et al., 2007; Harris et al., 2008), but its influence on crop raiding was insignificant in wet season as elephants disperse much more from riparian habitats during the time than in the dry season. Elephants dispersed from forests and national park "refugia", rendering distance to either forests or national park as environmental parameter insignificant, probably because Lupande area as the whole was well protected under Norwegian supported programme for over two decades, allowing free elephant movement. Roads did not play a role in deterring elephants from accessing crop fields as was determined at Nazinga Game Ranch, Burkina Faso, that road traffic did not disturb elephants (Hien et al., 2007). Lupande GMA had very limited 'feeder' road traffic, thereby, being unable to influence elephant crop raiding. Some farmers cleared buffers around their fields to stop elephants from entering their crop fields. Although the practice of creating buffers around crop fields might have increased the chances of the guards detecting approaching elephants, it was not effective by itself in preventing invasions. Majority of farmers $(79.26 \%)$ adopted more multi-angular or rectangular shaped crop fields than other field shapes, but differences in field shapes insignificantly (at $\mathrm{p}<0.05$ ) contributed to deterrence of crop raids.
Elevation did not also bear major impact on influencing crop depredation. Similarly, Linkie et al. (2007) and Sitati et al. (2003) in their separate studies did not find correlation between varying elevations and elephant distribution. According to Kinahan et al. (2007), ambient temperature was a more important determinant of landscape use in the savanna elephants than elevation.

\section{Counter-measures used by local farmers}

Farmers in the Luangwa Valley used a combination of methods to prevent or mitigate elephant crop raids. Use of combination of methods was recommended by Balfour et al. (2007) and Lamarque et al. (2009). However, among the combined methods in the Luangwa Valley, there were those more prominently applied by local farmers. Farmers applying Capsicum fencing and solar electric fencing were more likely to prevent elephant invasions than those commonly using traditional methods only.

In determining effectiveness of counter-measures, there was a challenge on how to isolate causes of responses by elephants. Existence of numerous confounding factors made it difficult to identify specific stimulus in each incident. Though elephants were deterred by traditional methods, eventually elephants became habituated, and these methods became ineffective. Although traditional methods were cheaper, non-lethal and easier to implement than most of other methods, they were ineffective in the long term. Due to the ineffective nature of traditional methods, family lineage and clans collaborated in the fight against crop raiders. Collaborative guarding along clan membership and sending early warning signs to the next farmer were among the strategies practiced. Reducing residence period and subsequently the amount of loss, contributed to the usefulness of the methods.

In the short term, disturbance counter-measures might prove to be effective but in long term became ineffective due to habituation as also reported by O'connell-Rodwell et al. (2000). Experimental methods had been tried in several sites in Africa (Osborn, 2002; Jones and Elliott, 2006; Graham and Ochieng, 2008). Largely targeting animal behaviour, results of such studies have shown that experimental repellents were non-lethal, but expensive and requiring high level of technology, which were prohibitive to local farmers for adoption and implementation (Osborn and Rasmussen, 1996). Even where the methods would be potentially effective, due to lack of consistency in proper implementation and difficulties in accessing inputs, experimental repellents depicted low and moderate effectiveness. Whereas solar powered electric fencing as physical barrier counter-measure was effective in restraining elephants, the account of DalalClayton and Child (2003) alluded to challenges of high fence maintenance costs and poor knowledge on fence establishment, needing technical expertise and close 
monitoring which were not available among local communities.

Shooting crop raiding elephants had long historical perspective in the Luangwa Valley (Marks, 1984). In the past, Balakrishnan and Ndhlovu (1992) contended control shooting had marginal effect in reducing crop damage in the Luangwa Valley. In line with the study by Lahm (1996), recognition of killing of elephants and other species on problem animal control programmes is merely a public relations activity in the Luangwa Valley and this exercise has remained as such. Even translocations, as one of the solutions to human-elephant interactions can present major challenges that include high costs, possibility of transferring elephant problem to another site and endurance of stress in transit (Garaï et al., 2004; Balfour et al., 2007).

Land use practices counter-measures further reflect the decisions made by local farmers. With increasing human population around Mfuwe (Kakumbi Chiefdom) in Lupande GMA (Figure 1), settlements and crop fields were not regulated, resulting in encroachment into prime wildlife areas. Changing of the cropping regimes was uncommon and that phenomenon was demonstrated in wide coverage of the mono-specific stands of crops in the agrarian landscape of the Luangwa Valley. Farmers' environmental indigenous knowledge was paramount (Winklerprins, 1999). Application of indigenous knowledge at base levels was critical to managing crop damage. The fundamental thrust was the reduction of interaction between people and elephants in the context of space and time achieved by manipulating their behaviours. Thus, as a coping strategy, local farmers have commenced clustering their settlements in order to collectively fight crop raiders.

\section{Implications for management}

HECs can erode local support for conservation, especially when costs outweigh benefits (Gadd, 2005; Svotwa et al., 2007). The success of conservation efforts on multiple land use of Lupande GMA hinges upon positive human-elephant interactions. Local communities' livelihoods should sustain their participation in natural resource conservation (Barrow and Murphree, 2001; Hulme and Murphree, 2001). This would require strengthening sustainable enterprises and developing social capital, especially as it relates to stakeholder relations, multi-level information communication and counter-measure innovations at base level. Causal factors must be quantified and tested prior to implementation of any management recommendations to ameliorate effects of elephant crop raiding. The assumption made here is that if environmental variables can be quantified, then, they can be monitored and controlled such that guided decision-making would lead to reduced crop depredation. Required are the effective early warning systems conveyed in form of proper use of predictive models and recommendations and precautionary measures put in place and active use of the deterrents prior to elephant crop raiding. Land use planning would play a major regulatory role in encouraging larger field sizes. Wanton field expansion may have its negating ramifications for habitat destruction. Under consolidation effort, smaller fields would be abandoned and consequently restored as wildlife habitats. Spatial segregation by fragmentation of crop fields increases "edge effect" and results in habitat shredding, land degradation and pattern alterations (Chapman et al., 2006), which consequently increases crop raiding incidences. Therefore, capacity building should be encouraged among the local farmers to enhance land use practices that minimize humanelephant conflicts. In addition, extension services to the local farmers would be essential to provide information on high risk factors currently at play. However, with availability of new data and expert knowledge, predictive models require revising periodically to remain responsive to dynamics in human-wildlife interactions.

\section{Conclusion}

Myriad of risk factors may play part in influencing crop raiding individually or collectively, but only few of them would significantly act to determine the occurrence of elephant crop raiding. Isolation of these risk factors would serve as early warning elements for site specific remedial measures. Therefore, recognizing how individual or collective environmental factors for elephant crop raiding collectively impact on the local farmer was the focus of this article. Predictions of elephant crop raiding stress the importance of adherence to specific recommendations for each HEC site. To underline the relevance of predictions and secure co-management stakeholders' undivided efforts in tackling elephant crop invasions, it is important to understand elephant crop raiding processes and patterns. The implications of ignoring processes and relationships, particularly related to land use practices can be injurious to the success of the battle towards food security for rural communities living in protected areas which would usurp their support for wildlife conservation. The predictive models inform and establish generic frameworks for determining key environmental variables influencing crop depredation that require attention.

\section{ACKNOWLEDGEMENTS}

Safari Club International (SCI) supported this study with a grant at Tshwane University of Technology (TUT), Pretoria, South Africa. Zambia Wildlife Authority provided its fated support to the study. The authors are also particularly grateful to the Regional Manager, $\mathrm{M}$. Mushimbalume and Area Ecologist, P. Sichone, who 
facilitated field data collection by field assistants, for whom we are indebted with great thanks. The map in this publication was gratefully produced by Chaka Kaumba, GIS specialist.

\section{REFERENCES}

Archer DR (1971). Rainfall. In: Davies DH (ed.). Zambia in Maps. University of London Press, London pp. 1-20.

Balakrishnan M, Ndholvu DE (1992). Wildlife utilization and local people: A case study of upper Lupande Game Management Area, Zambia. Environ. Conserv. 19:135-144.

Balfour D, Dublin HT, Fennessy J, Gibson D, Niskanen L, Whyte IJ (eds.) (2007). Review of options for managing the impacts of locally overabundant African elephants. IUCN, Gland p. 80.

Balmford A, Moore JL, Brooks T, Burgess N, Hansen LA, Williams P, Rahbek C (2001). Conservation conflicts across Africa. Science 291:2616-2619.

Barnes RFW, Duiure UF, Danquah E, Boafo Y, Nandjui A, Hema EM, Manford M (2006). Crop raiding elephants and the moon. Afr. J. Ecol. 45:112-115.

Barrow E, Murphree M (2001). Community conservation from concept to practice: A framework, In: Hulme D and Murphree M (eds.), African wildlife and livelihoods: The promise and performance of community oonservation. James Currey, New Hampshire pp. 24-37.

Bradburn N, Sudman S, Wansink B (2004). Asking questions: The definitive guide to questionnaire design - for market research, political polls, and social and health questionnaires. Jossey-Bass, California.

Chamaillé-Jammes S, Valeix M, Fritz H (2007). Managing heterogeneity in elephant distribution: interactions between elephant population density and surface-water availability. J. Appl. Ecol. 44:625-633.

Chapman CA, Lawes MJ, Eeley HA (2006). What hope for African primate diversity? Afr. J. Ecol. 44:116-133.

Chiyo PI, Cochrane EP, Naughton L, Basuta GI (2005). Temporal patterns of crop raiding by elephants: A response to changes in forage quality or crop availability? Afr. J. Ecol. 43:48-55.

Crawley MJ (1994). GLIM for ecologists. Blackwell Scientific Publications, Oxford.

CSO (Central Statistical Office) (2003). Zambia 2000 census of population and housing. Central Statistical Office, Lusaka.

Dalal-Clayton B, Child B (2003). Lessons from Luangwa: The story of the Luangwa Integrated Resource Development Project, Zambia. International Institute for Environment and Development, London.

Danquah E, Oppong SK, Sam MK (2006). Aspects of elephant crop raiding behaviour in the Kakum Conservation Area, Ghana. Nat. Faune 21(2):15-19

FAO (2008). Challenges for sustainable land management for food security in Africa. $25^{\text {th }}$ Regional Conference for Africa, Nairobi, Kenya. Information paper 5:5.

Fowler J, Cohen L, Jarvis P (2006). Practical statistics for field biology. $2^{\text {nd }}$ Ed. John Wiley \& Sons Ltd., England.

Gadd ME (2005). Conservation outside of parks: Attitudes of local people in Laikipia, Kenya. Environ. Conserv. 32(1):50-63.

Garaï ME, Slotow R, Carr RD, Reilly B (2004). Elephant reintroductions to small fenced reserves in South Africa. Pachyderm 37:28-36.

Gausan A, Edwards TC, Hastie T (2002). Generalized linear and generalized additive models in studies of species distributions: Setting the scene. Ecol. Model. 157:89-100.

Gilvear D, Winterbottom S, Sichingabula H (2000). Character of channel platform change and meander development: Luangwa River, Zambia. Earth Surf. Proc. Land. 25(4):421-436.

Graham MD, Ochieng T (2008). Uptake and performance of farm based measures for reducing crop raiding by elephants Loxodonta africana among smallholder farms in Laikipia District, Kenya. Oryx 42(1):76-82.

Harris GM, Russell GJ, van Aarde RI, Pimm SL (2008). Rules of habitat use by elephants Loxodonta africana in Southern Africa: Insights for regional management. Oryx 42(1):66-75.
Hien BM, Jenks JA, Klaver RW, Wicks ZW (2007). Determinants of elephant distribution at Nazinga Game Ranch, Burkina Faso. Pachyderm 42:70-80.

Hoare RE (1999). Determinants of human-elephant conflict in land use mosaic. J. Appl. Ecol. 36:689-700.

Hoare RE (2001). A decision support system for managing humanelephant conflict situation in Africa. The World Conservation Union, Nairobi.

Hulme D, Murphree M (2001). Community conservation as policy: Promise and performance. In: Hulme D and Murphree $M$ (eds.) African Wildlife and Livelihoods: The Promise and Performance of Community Conservation. James Currey, New Hampshire pp.280297.

Jones BT, Elliott WJ (2006). Human wildlife conflict in Namibia: experiences from a portfolio of practical solutions. Nat. Faune 21(2):20-25.

Junker J, van Aarde RJ, Ferreira SM (2008). Temporal trends in elephant Loxodonta africana numbers and densities in northern Botswana: is the population really increasing? Oryx 42:58-65.

Kagoro-Rugunda G (2004). Crop raiding around Lake Mburo National Park, Uganda. Afr. J. Ecol. 42:32-41.

Kinahan AA, Pimm SL, van Aarde RJ (2007). Ambient temperature as determinant of landscape use in the savanna elephant, Loxodonta africana. J. Thermal Biol. 32:47-58.

Koenig WD (1999). Spatial autocorrelation of ecological phenomena. Trends Ecol. Evol. 14:22-26.

Lahm SA (1996). A nationwide survey of crop raiding by elephants and other species in Gabon. Pachyderm 21:69-77.

Lamarque F, Anderson J, Fergusson R, Lagrange M, Osei-Owusu Y, Bakker $L$ (2009). Human-wildlife conflict in Africa: Causes, consequences and management strategies. FAO, Rome.

Lewis DM (2007). Opportunities and constraints for protected area management through increased connectivity to local livelihood needs in surrounding border areas: Lessons from Luangwa Valley, Zambia. In: Redford KH and Fearn E (eds.). Protected areas and human livelihoods. Wildlife Conservation Society, New York, 32, pp.38-49.

Lewis DM, Phiri A (1998). Wildlife snaring - an indicator of community response to a community based conservation project. Oryx 32(2):111-121.

Linkie M, Dinata Y, Nofrianto A, Leader-Williams N (2007). Patterns and perceptions of wildlife crop raiding in and around Kerinci Seblat National Park, Sumatra. Anim. Conserv. 10:127-135.

Madden $F$ (2006). Human-wildlife conflict: a case for collaboration. Nat. Faune 21(2):8-9.

Malima C, Hoare R, Blanc JJ (2005). Systematic recording of humanelephant conflict: a case study in south eastern Tanzania. Pachyderm 38:29-38.

Marks SA (1984). The imperial lion; human dimensions of wildlife management in Central Africa. Westview Press, Colorado.

McIntyre C (2004). Zambia: the Bradt travel guide. Third edition. Chalfont, Bradt, St Peter.

Naughton-Treves L (1998). Predicting patterns of crop damage by wildlife around Kibale National Park, Uganda. Conserv. Biol. 12:156168

Nicholls AO (1989). How to make biological surveys go further with generalized linear models. Biol. Conserv. 50:51-75.

Nyhus PJ, Osofsky PR, Madden FM, Fisher H (2005). Bearing the costs of human-wildlife conflict: The challenges of wildlife compensation schemes. In: Woodroffe R, Thirgood S and Rabinowitz A (eds.). People and wildlife: Conflict or coexistence? The Zoological Society of London. Cambridge University Press, Cambridge pp. 107-121.

Nyirenda VR, Chansa WC, Myburgh WJ, Reilly BK (2011). Wildlife crop predation in the Luangwa Valley, eastern Zambia. J. Ecol. Nat. Environ. 12(8):158-180.

O'Connell-Rodwell CE, Rodwell T, Rice M, Hart LA (2000). Living with the modern conservation paradigm: Can agricultural communities coexist with elephant? A five - year case study in East Caprivi, Namibia. Biol. Conserv. 93:381-391.

Osborn FV (2002). Capsicum oleoresin as an elephant repellent: field trails in the communal lands of Zimbabwe. J. Wildlife Manag. 66(3):674-677.

Osborn FV, Rasmussen LEL (1996). Evidence for the effectiveness of 
an Oleoresin capsicum aerosol as a repellent against wild elephant in Zimbabwe. Pachyderm 21:55-64.

Parker GE, Osborn FV (2001). Dual season crop damage by elephants in eastern Zambezi Valley, Zimbabwe. Pachyderm 30:49-56.

Phiri PSM (1994). The relevance of plant taxonomic information for the conservation of the low altitude Luangwa Valley ecosystem. In: Seyani JH and Chikuni AC (eds.). Proceedings of the XIII ${ }^{\text {th }}$ plenary meeting AETFAT, pp. 903-910.

Reilly BK, Reilly Y (2003). Auditing wildlife. Koedoe 46(2):97-102.

Riley S, Siemer W, Decker D, Carpenter L, Organ J, Berchielli L (2003). Adaptive impact management: An integrative approach to wildlife management. Hum. Dimens. Wildl. 8:81-95.

Selvin S (2004). Statistical analysis of epidemiological data, $3^{\text {rd }}$ ed. Oxford University Press, New York.

Simasiku P, Simwanza HI, Tembo G, Bandyopandhyay S, Pavy JM (2008). The impact of wildlife management policies on communities and conservation in Game Management Areas in Zambia: message to policy makers. Edited by CL Buus, World Bank, Lusaka.

Simukonda C (2008). National-wide large mammal surveys and population estimates. New Horizon Printing Press, Lusaka.
Sitati NW, Walpole MJ, Leader-Williams N (2005). Factors affecting susceptibility of farms to crop raiding by African elephants: Using a predictive model to mitigate conflict. J. Appl. Ecol. 42:1175-1182.

Sitati NW, Walpole MJ, Smith RJ, Leader-Williams N (2003). Predictive spatial aspects of human-elephant conflict. J. Appl. Ecol. 40:667-677.

Smith P (1998). A reconnaissance survey of the vegetation of the North Luangwa National Park, Zambia. Bothalia 28(2):197-211.

Svotwa E, Ngwenya J, Manyanhaire OT, Jiyane J (2007). Residents' perception of the human wildlife conflict in Kariba Urban. J. Sustain. Dev. Afr. 9:178-191.

Taylor RD (1993). Elephant management in Nyami Nyami District, Zimbabwe: Turning a liability into an asset. Pachyderm 17:19-29.

Winklerprins AMG (1999). Local soil knowledge: a tool for sustainable land management. Soc. Nat. Resour. 12:151-161.

Wittemyer G, Elsen P, Bean WT, Burton ACO, Brashares JS (2008). Accelerated human population growth at protected area edges. Science 321:123-126. 